\title{
Design of High Gain, Bandwidth and Efficient Double Split Ring Slotted Antenna with Swastika Shape EBG Structures at $21.29 \mathrm{GHz}$ for High Data Rate Communications
}

\author{
Karteek Viswanadha \\ PhD Scholar \\ Delhi Technological University \\ India
}

\author{
N. S. Raghava \\ Professor \\ Delhi Technological University \\ India
}

\begin{abstract}
Microstrip patch antennas are frequently used in many integrated circuits due to their compactness, planar nature and ease of integration. These antennas are modified according to the designer's application and specifications. One such modified antenna is slotted antenna. Slotted antennas are usually used to enhance gain, bandwidth and low VSWR. Increasing slots on the patch will enhance bandwidth with the degradation of gain. The problem of surface waves also arises with the increment in slots. Many structures like Electromagnetic Bandgap Structures (EBG), Defective Ground Structures (DGS) are proposed in order to reduce the surface waves. This paper presents the detailed design of double split ring slotted patch antenna mounted on the swastika EBG structure at $21.29 \mathrm{GHz}$. The proposed antenna is simulated using Advance Design System-2016. Gain and bandwidth of the proposed antenna are observed to be $11.92 \mathrm{~dB}$ and $3.2 \mathrm{GHz}$ respectively.
\end{abstract}

\section{Keywords}

Microstrip patch, split ring slot, swastika EBG, VSWR, DGS

\section{INTRODUCTION}

Many planar antennas like Planar Inverted F-Antenna (PIFA), microstrip patch antenna are frequently used due to their planar nature. Planar nature of these antennas not only eases the process of integration but also makes the designer to modify the antennas according to his specifications and application. Many methods are proposed to enhance bandwidth, gain in microstrip patch antennas. One of the methods is etching the slots on the patch with appropriate dimensions of the slot. Bandwidth is enhanced by feeding the slot directly [1]. Usually patch is fed through inset in order to enhance gain and bandwidth. ' $\mathrm{H}$ '-shaped slot is made on the patch and thus making the patch to radiate at multiple bands [2]. ' $\mathrm{E}$ ' and ' $\mathrm{H}$ '-shape slotted patches are fed with L-probe and thereby enhancing the bandwidth to $400 \mathrm{MHz}$ [3]. Antenna is mounted on a very thin substrate making it a high gain antenna. By deploying a very thin dielectric substrate, bandwidth of the patch can be enhanced. However, there should be some reasonable trade-off between the size and bandwidth of an antenna. Proper impedance matching can be achieved using appropriate feeding techniques and subsequently return loss will be reduced with the increase in the impedance bandwidth [4]. Compact patch antennas are proposed with enhanced bandwidth by tuning the slot dimensions [5]-[6]. Slots are etched on the diagonally on the patch and thereby enhancing bandwidth by $18 \mathrm{MHz}$ with bore sight gain of $3.3 \mathrm{~dB}$ [7]. A compatible ring shaped microstrip antenna with electrical length of $0.297 \lambda_{o} \times \quad 0.297 \lambda_{o}$ is proposed in [8]. Outer, middle and inner ring electrical lengths of the antenna are $4 \mathrm{mmx} 4 \mathrm{~mm}, 2 \mathrm{mmx} 2.4 \mathrm{~mm}$ and $0.5 \mathrm{mmx} 0.6 \mathrm{~mm}$ respectively. The reflection coefficient of antenna is below $-10 \mathrm{~dB}$ from $58.8 \mathrm{GHz}$ to $61.58 \mathrm{GHz}$ [8]. Four ring shaped slots are etched on the patch which made the proposed antenna circularly polarized [9]. Moreover, varying the width of the ring changes the operating frequency. Hexagonal microstrip patch antenna based on its equivalence with rectangular and circular patch antennas is proposed in [10]. Rectangular slots are etched on the alternate sides of the hexagon and thereby enhancing the bandwidth of the antenna by $4.42 \mathrm{MHz}$. Patch antenna is mounted on Embedded Uniplanar Compact Electromagnetic band-gap (E-UC-EBG) and shorting vias are used to short the patch and the EBG structure [11]. The gap between the vias is chosen to be $1 / 8^{\text {th }}$ of the wavelength in order to enhance the bandwidth of operation. Hexagonal holes are etched in the ground plane to increase the efficiency of patch antenna structure [12]. Square holes etched on the ground plane also increase the efficiency and gain of the patch antenna [13].

\section{DESIGN OF THE PROPOSED ANTENNA}

A patch antenna with five split rings i.e. four at the corners and one at the centre has been designed. Figure 1(a) shows the shape of the slot length $(l)$ and width $(w)$ of the ring is chosen to $0.11 \mathrm{~mm}$ and $0.01 \mathrm{~mm}$ respectively. The spacing $\left(s_{1}\right)$ of two rings is taken to be $0.127 \mathrm{~mm}$ and the spacing $(s)$ between the ring and the base is taken as $0.127 \mathrm{~mm}$. The height of the rings (h) from the base is taken as $0.2 \mathrm{~mm}$. The slot acts as a band pass filter since the spacing between the rings is equivalent to an inductor and the width of the slot is equivalent to a capacitor. The length (L) and width (W) of the patch is taken as $7.7 \mathrm{~mm}$ and $11.81 \mathrm{~mm}$ respectively. The inset feed of length $\left(l_{1}\right) 6 \mathrm{~mm}$ is inserted in to the patch. Figure 1(b) shows the designed double split ring slotted patch antenna. The whole device is mounted on the ground plane on RT Rogers $5880\left(\varepsilon_{r}=2.2\right)$ with the height of $2.5 \mathrm{~mm}$ from the ground plane of dimensions $15.4 \mathrm{~mm}$ and $23.62 \mathrm{~mm}$ respectively. Electrical length of the proposed antenna is taken to be $0.8881 \lambda_{o} \times 0.7298 \lambda_{o}$. Double split ring slotted patch antenna shown in figure $1(\mathrm{~b})$ is designed to resonate at $24.4 \mathrm{GHz}$. 


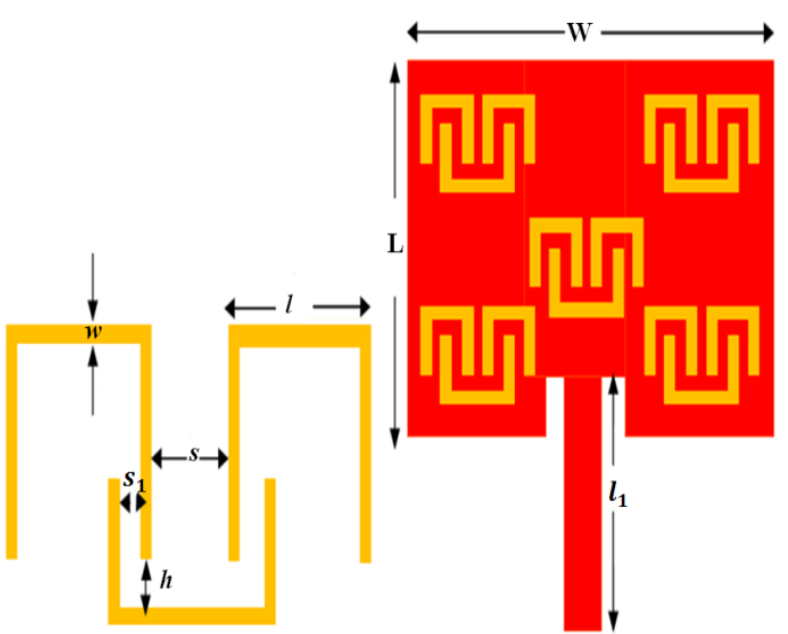

Fig.1(a): Double split ring slot

Fig.1(b): Double split ring slotted patch

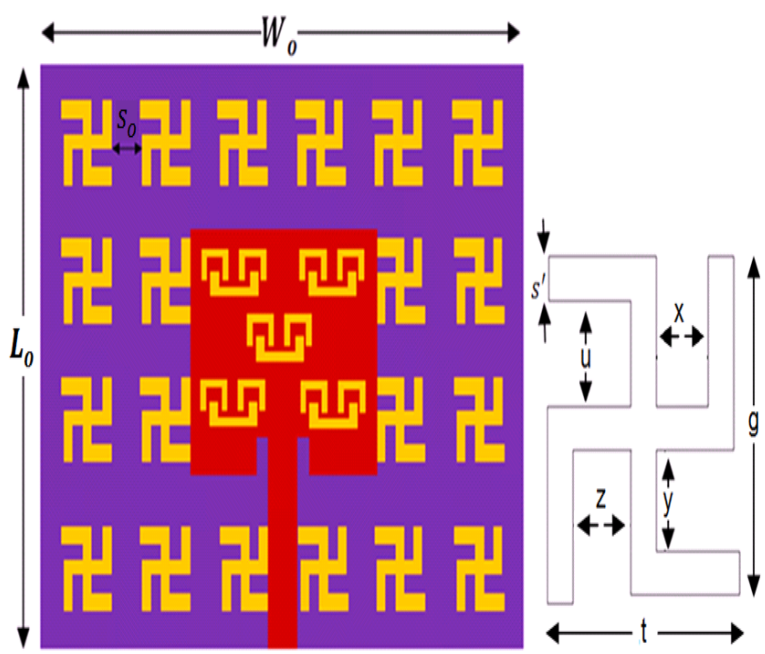

Fig.2(a): Double split ring slotted antenna with swastika EBG

Fig 2(b): Swastika slot

Figure.2 (a) shows the double spilt ring slotted antenna mounted on the ground plane etched with swastika shape slots commonly known as Electromagnetic Bandgap Structures (EBG). The proposed EBG structure is designed with total of 20 slots leaving the portion below the plane of the patch unetched. Width $\left(W_{o}\right)$ and length $\left(L_{o}\right)$ of the ground plane are chosen to be $29.525 \mathrm{~mm}$ and $19.25 \mathrm{~mm}$ respectively. As shown in figure.2 (a), width ( $\mathrm{t}$ ) and length ( $\mathrm{g}$ ) of the whole swastika slot are chosen to be $2.5 \mathrm{~mm}$ and $3.5 \mathrm{~mm}$ respectively. Gap (x, z) between the vertically parallel arms are taken as $0.4 \mathrm{~mm}$ and $0.6 \mathrm{~mm}$ respectively. Width $\left(s^{\prime}\right)$ of all the arms of the slot is taken as $0.5 \mathrm{~mm}$. Spacing (y, u) between the horizontally parallel arms is chosen to be $1 \mathrm{~mm}$ and $1 \mathrm{~mm}$ respectively. Spacing $\left(s_{o}\right)$ between two swastikas is taken as $0.75 \mathrm{~mm}$. Slotted patch is placed exactly at the centre of the EBG structure for the best results.

The equivalent circuit of a swastika slot is shown in figure. 3

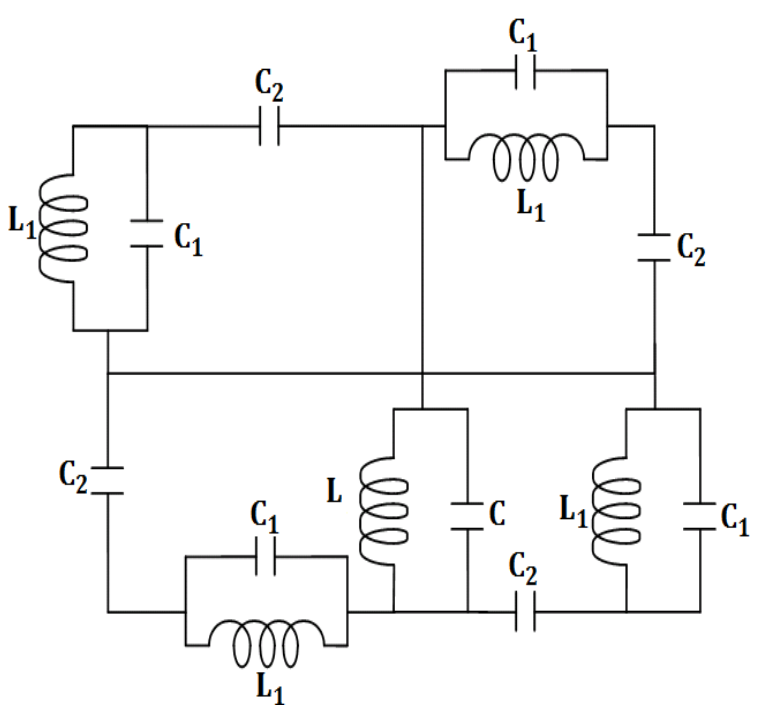

Fig.3: Equivalent circuit of swastika slot

The transfer function of the model shown in figure. 3 is given by:

$\mathrm{H}(\mathrm{s})$

$=\frac{2 L_{1} s^{4}\left(C\left(C_{1}+C_{2}\right)+C_{1} C_{2}\right)+s^{2}\left(L_{1}\left(C_{1}+C_{2}\right)+L C\right)+1}{\left(L_{C L} C_{1} s^{4}+s^{2}\left(L C+L_{1} C_{1}\right)+1\right) C_{2} s}$

The approximate resonant frequencies of the slot are obtained as:

$\omega_{\mathrm{o}}^{\prime}=\frac{1}{\sqrt{\mathrm{LC}}} \& \omega_{\mathrm{o}}^{\prime \prime}=\frac{1}{\sqrt{\mathrm{L}_{1} \mathrm{C}_{1}}}$

Resonant frequencies are calculated by assuming that swastika is symmetrical. As the proposed swastika is asymmetrical, the two resonant frequencies will coincide and thus making the EBG structure highly selective.

\section{RESULTS AND DISCUSSION}

The proposed antenna is simulated in ADS-2016 momentum and figure. 4 shows the layout of the proposed antenna structure in radiating mode.

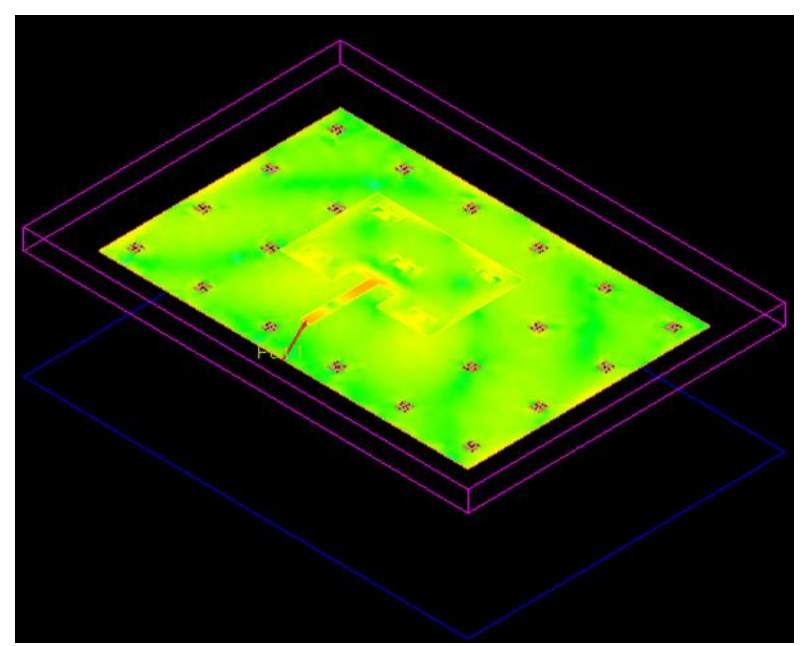

Fig.4: 3-D model of the proposed antenna.

Figure.5 shows the magnitude and phase plots of reflection coefficient of the proposed antenna structure. 


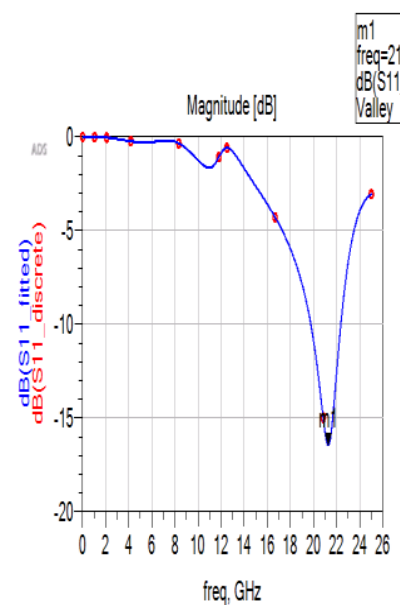

$\mathrm{m1} 2.29 \mathrm{GH}$

Valley

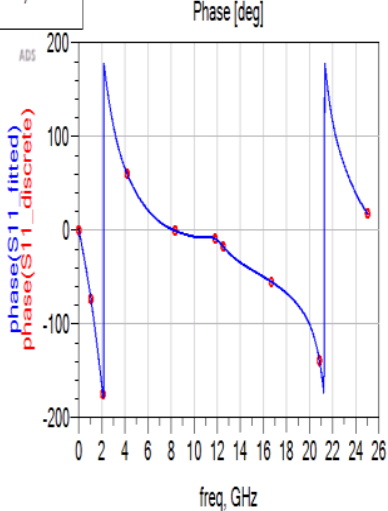

Fig.5: Magnitude and phase plots of reflection coefficient

Figure.6 shows the 2-D pattern of gain, directivity, electric and magnetic far fields.
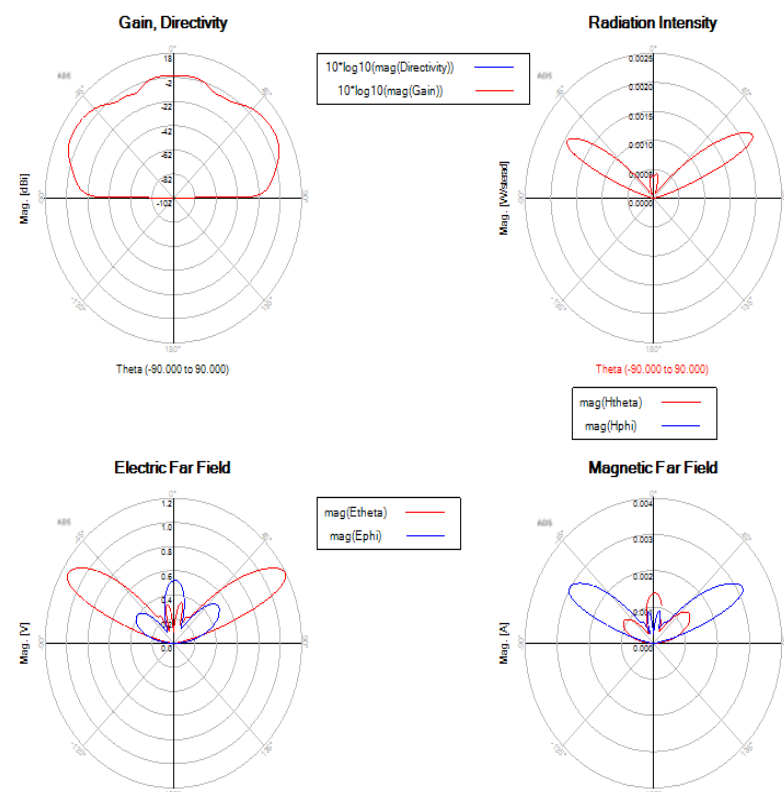

Fig.6: 2-D pattern of all the parameters of the proposed antenna

Figure.6 shows the 3-D radiation pattern of the proposed antenna structure and dual switched beams with dough-nut shaped 3-D radiation pattern are observed

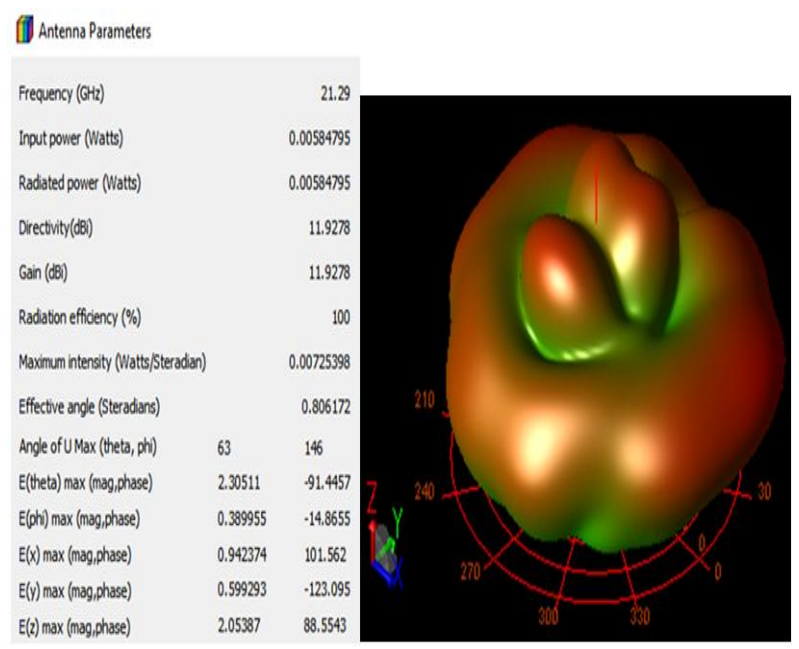

Fig.7: 3-D radiation pattern of the antenna

The slot dimensions are varied using ADS-2016 momentum to layout converter cum tuner. The performance parameters are highly affected with the $1 \%$ change in the dimensions of the swastika slot.Table.1 shows the performance parameters of the proposed antenna.

Table 1. Performance parameters of the proposed antenna

\begin{tabular}{|c|c|c|c|}
\hline $\begin{array}{c}\text { Gain } \\
(\mathbf{d B})\end{array}$ & $\begin{array}{c}\text { Bandwidth } \\
\text { (GHz) }\end{array}$ & $\begin{array}{c}\text { Directivity } \\
\text { (dB) }\end{array}$ & $\begin{array}{c}\text { Efficiency } \\
(\mathbf{\%})\end{array}$ \\
\hline 11.92 & 3.2 & 11.92 & 100 \\
\hline
\end{tabular}

\section{CONCLUSION}

A double split ring slotted patch antenna mounted on swastika EBG is proposed and analyzed using Agilent ADS-2016.By etching swastika slots on the ground plane, it is observed that bandwidth of $3.2 \mathrm{GHz}$ with the gain of $11.92 \mathrm{~dB}$ is obtained for the proposed antenna structure. The structure can be suitably used for point-to-point applications. In the future the structure is expected to be modified for nantenna using ADS-2016 software.

\section{REFERENCES}

[1] Norbahiah Misran, Mohammed N. Shakib, Mohammad T. Islam, And Baharudin Yatim, "Design Analysis Of A Slotted Microstrip Antenna For Wireless Communication", International Scholarly And Scientific Research \& Innovation, World Academy Of Science, Engineering And Technology, Vol:3, No:1, 2009,Pp.3436

[2] Sweety Goyal And Balraj Singh Sidhu, "A Compact Slotted Microstrip Antenna For Multiband Applications", International Journal Of Scientific Research Engineering \& Technology (IJSRET), Vol: 3, Issue:7, October 2014, Pp.1059-1063.

[3] Mohammad Tariqul Islam,Norbahiah Misran, Mohamaad Nazmus Shakib And Baharudin Yatim, "Analysis Of LProbe Fed Slotted Microstrip Patch Antenna", IEEE International Conference On Communication Systems, ISBN: 978-1-4244-2423-8, 2008, China, Pp.380-383.

[4] Wei He, Ronghong Jin, Junping Geng, "E-Shape Patch With Wideband And Circular Polarization For Millimeter-Wave Communication", IEEE Transactions On Antennas And Propagation, Vol: 56, Issue:3, 2008, Pp.893-895. 
[5] Nasimuddin, Zhi Ning Chen And Xianming Qing, "Asymmetric-Circular Shaped Slotted Microstrip Antennas For Circular Polarization And RFID Applications", IEEE Transactions On Antennas And Propagation,Vol: 58, Issue:12, 2010, Pp.3821-3828.

[6] Norbahiah Misran, Mohammed N. Shakib, Mohammad T. Islam, And Baharudin Yatim, "Analysis Of Broadband Slotted Microstrip Patch Antenna", IEEE International Conference On Computer And Information Technology, ISBN: 978-1-4244-2135-0, 2008, Bangladesh, Pp.758761

[7] Nasimuddin, Zhi Ning Chen And Xianming Qing, "Slotted Microstrip Antennas For Circular Polarization With Compact Size", IEEE Transactions On Antennas And Propagation, Vol:55, Issue:2, 2013, Pp.124-137.

[8] KK Sharma And Ravi Kumara Goyal, "Slotted Microstrip Patch Antenna At 60ghz For Point To Point Communication", IEEE International Conference On Communication Networks, ISBN: 978-1-5090-0051-7, Gwalior, 2015, Pp.371-373.

[9] Nasimuddin, Zhi Ning Chen And Xianming Qing, "Circularly Polarized Ring-Slotted-Microstrip Antenna", IEEE Asia-Pacific Conference On Antennas And
Propagation,ISBN: 978-1-4799-8897-6, 2015, Indonesia, Pp.203-204.

[10] Shivraj Rathod, Arpan Shah, Devichand Rathod,Mangesh Dhakane, Priyanka Deosarkar, "Dual Band Slotted Hexagonal Microstrip Antenna", IEEE International Conference On Computing Communication Control And Automation,ISBN: 978-14799-6892-3, 2015, Pune, Pp.220-222.

[11] Shivam Guatam, Komalbir And N. S. Raghava, "Design And Analysis Of Uniplanar Compact Electromagnetic Bandgap Structures,", Progress In Electromagnetics Research Symposium, Prague, Czech Republic, 2015, Pp. $2092-2094$

[12] Amol Choudhary, N. S. Raghava, Animesh Biswas And Asok De, "A Highly Efficient Rectangular Microstrip Antenna With Hexagonal Holes As An Electromagnetic Bandgap Structure In The Ground Plane", Recent Advances In Microwave Theory And Applications, India, 2008, Pp.152-153

[13] Amol Choudhary, N. S. Raghava And Asok De, "A High Gain Rectangular Patch Radiator With Square Holes In The Ground Plane," European Electromagnetic Symposium, Switzerland, 2008. 